\title{
Regenerative endodontic: current progress
}

\author{
Suresh Kotumachagi Sangappa ${ }^{1}$, Nagarathna Javanaiahar ${ }^{2}$, A. Pravin Kumar ${ }^{3}$, \\ Shruti ${ }^{4}$. \\ ${ }^{I}$ (Professor \& Head of the Department, Pedodontics \& Preventive Dentistry, Government Dental College \& \\ Research Institute, Bangalore- 560002, India) \\ ${ }_{2}^{2}$ (Senior Lecturer Pedodontics \& Preventive Dentistry, Government Dental College \& Research Institute, \\ Bangalore- 560002, India) \\ ${ }^{3 \& 4}$ (Post Graduate student, Department of Pedodontics \& Preventive Dentistry, Government Dental College \& \\ Research Institute, Bangalore- 560002, India)
}

\begin{abstract}
Dental trauma occurs frequently in children and often can lead to pulpal necrosis. When pulp tissue becomes necrotic in immature teeth, the prognosis of the teeth is compromised because of the root(s) presents several challenges including difficulties in cleaning and shaping large canals with open apices, obturation of canals with open apices, and potential root fractures caused by thin and lor weakened root walls. An optimal approach for treating the immature permanent tooth with necrotic pulp would be to regenerate functional pulpal tissue that fosters continued root development and immune competency. This article will review the early attempts to regenerate pulp tissue and current progress and feasible strategies of tissue engineering in endodontics, and dental pulp regeneration.
\end{abstract}

Keywords: Dental pulp stem cells, immature teeth with open apices, Pulp-dentin complex regeneration, Pulp revascularization, Regenerative endodontics.

\section{Introduction}

Trauma to the anterior teeth, commonly found among young children, accounts for one third of all traumatic injuries in boys and one fourth of all injuries in girls $(1,2)$. Population-based studies from around the world indicate that the prevalence of dental trauma injuries is about $4 \%-59 \%$, with the majority of cases occurring in incisors and often can lead to pulpal necrosis (3). The occurrence of pulpal necrosis in the permanent but immature tooth often represents a challenging clinical situation because the thin and often short roots increase the risk of subsequent fracture. Current approaches for treating the traumatized immature tooth with pulpal necrosis do not reliably achieve the desired clinical outcomes, consisting of healing of apical periodontitis, promotion of continued root development, and restoration of the functional competence of pulpal tissue. An optimal approach for treating the immature permanent tooth with a necrotic pulp would be to regenerate functional pulpal tissue (4). Procedures attempting to preserve the potentially remaining dental pulp stem cells and mesenchymal stem cells of the apical papilla can result in canal revascularization and the completion of root maturation. It encourages a longer and thicker root to develop thus decreasing the propensity of long term root fracture (5).

The research on regeneration of a pulp-dentin complex has a long history. It was introduced by Ostby (6) in 1961, and in 1966, Rule and Winter (7) documented root development and apical barrier formation in cases of pulpal necrosis in children. In 1971, Nygaard-Ostby \& Hjortdal performed studies that can be considered the fore runner of pulpal regeneration (8). The results of these studies were variable. However, the materials and instruments available 40-50 years ago were probably not sufficient and adequate. Thus, with advances in basic research, recent reports and studies have shown successful application of tissue engineering and regeneration in the field of dentistry, using greatly improved materials, instruments, and medications. So it could be possible to effectively disinfect an infected pulp, artificially place a scaffold and/or by harnessing the natural regenerative potential of the dental pulp, and then effectively seal the access cavity to resist subsequent infection.

The American Association of Endodontists' Glossary of Endodontic Terms defines regenerative endodontics as "biologically-based procedures designed to physiologically replace damaged tooth structures, including dentin and root structures, as well as cells of the pulp-dentin complex"(9). Presently, two concepts exist in regenerative endodontics to treat non-vital infected teeth - one is the active pursuit of pulp-dentine regeneration to implant or regrow pulp tissue based on tissue engineering principles, and the other in which new living pulp tissue is expected to form from the cells present in the apical end of the teeth itself, by creating an environment conductive to revascularization of the root canal system and allowing continued root development. 


\section{Tissue Engineering}

Tissue engineering is an interdisciplinary field that applies the principles of engineering and life sciences toward the development of biological substitutes that restore, maintain, or improve tissue function (1). Tissue engineering approach requires the three main key elements (triad): stem cells, scaffold of extracellular matrix (ECM) and growth factors (signals for morphogenesis) $(10,11)$.

\subsection{Stem cells}

A stem cell is defined as a cell that has the ability to continuously divide and produce progeny cells that differentiate (develop) into various other types of cells or tissues(12). Stem cells are further delineated in terms of whether the cells are embryonic stem cells (fetal stem cells) or post-natal (adult) stem cells (13). Embryonic (fetal) stem cells are derived from embryos (blastocysts), are pluripotent, can self-renew and have plasticity greater than the post-natal stem cells (14). Thus, these stem cells are more valuable in tissue engineering but are not used readily because of the controversial ethical and legal issues linked to their sourcing. Currently, a lot of focus has been given to post-natal (adult) stem cells (15).

Postnatal stem cells have been found in almost all body tissues (16), including dental tissues $(17,18)$. To date, five types of human dental stem cells have been isolated and characterized:

a) Dental pulp stem cells (DPSCs). (19)

b) Stem cells from human exfoliated deciduous teeth (SHED). (20)

c) Stem cells from apical papillae (SCAP). $(21,22)$

d) Periodontal ligament stem cells (PDLSCs). (23)

e) Dental follicle progenitor cells (DFPCs). (24)

All types of postnatal dental stem cells studied have mesenchymal stem cell-like qualities, such as capacity for self-renewal and multilineage differentiation. DPSCs exhibited a higher proliferation rate compared with bone marrow stromal stem cells (BMSCs) in vitro. Both DPSCs and BMSSCs express smooth muscle and endothelial markers. DPSCs express dentin sialophosphoprotein (DSPP), a gene that encodes for dentin sialoprotein and dentin phosphoprotein, which is important for dentinogenesis and they are also able to generate a dentin pulp-like complex by in vivo transplantation (25). From both DPSCs and SHED, tissue similar to normal dentin-pulp is reported to be regenerated which can be later on used for regenerative endodontics (26). But SHED are retrieved from a tissue that is 'disposable' and readily accessible. SHED also show higher proliferation capability, abundant cell supply and painless stem-cell collection with minimal invasion, so SHED could be a desirable option as a cell source for regenerative endodontics;(27) however, in comparision, DPSCs show higher inclination towards neuronal lineage (28). SCAP have higher proliferation rate as compared to DPSCs. They appear to be the source of primary odontoblasts that are responsible for root dentin formation whereas DPSCs are the likely source of replacement odontoblast. SCAP represent early progenitor cells (22), so whether SCAP are a more suitable stem-cell source than DPSCs and SHED require further investigation. Viable periodontal ligament is reported to be generated from PDLSCs (29).

There are two major approaches to deliver stem cells into the root canal for pulp regeneration:

\subsubsection{Cell transplantation}

This involves direct delivery of autologous or allogeneic stem cells into the root canals. Studies in animals have shown promising results with this approach for regenerative endodontics (30). There is still a need for good in situ models for human regenerative procedures, as they would be used on patients. The major roadblocks for clinical translation are immune rejection potential (for allogeneic cells), regulatory approval for using in patients, and high cost. Immunocompatible off-the-shelf allogeneic stem cells could potentially be used to formulate a viable commercial product to use for total dentin-pulp regeneration in endodontic practice (31).

\subsubsection{Cell homing}

This involves the use of chemotactic factors like Stromal Cell Derived Factor (SDF)-1 that can induce migration of stem cells from the periapical area into the root canal. Immune rejection is therefore not an issue. This has been investigated in animal models as an adjunct to stem cell transplantation, but not as a standalone technique (30). The regulatory approval process to use this technique in human patients would be much easier, and the cost much lower. However, the results may depend on the distance that cells need to migrate, so the longer the root length, the less favorable the prognosis would be (31).

The first manufactured medicament based on allogeneic stem cell transplantation was recently granted regulatory approval to treat children suffering from graft-versus-host disease (GVHD). Stem cell banking of Stem Cells from Exfoliated Deciduous teeth (SHED) and DPSCs from extracted third molars has already been commercialized in anticipation of clinical therapeutic applications. Inflamed pulp tissues are currently discarded as medical waste, but they have been shown to contain stem cells with regenerative potential and may be 
considered as an alternative and more attainable source of DPSCs (32). The timeline for translation of tissue engineering into clinical endodontic practice remains to be seen, but there already appears to be an explosion of basic science research in this field.

\subsection{Scaffold}

A scaffolds provide support for cell organization, proliferation, differentiation and vascularization (33). A scaffold should be porous to allow for placement of cells and also be biocompatible with host tissue (34). It should be biodegradable and should degrade gradually so that it is replaced by regenerative tissue (35). It should be effective for transport of nutrients and waste (36). Current Regenerative endodontic procedures have utilized dentin as well as the blood clot (37) or platelet-rich plasma (38) to provide scaffolds in the root canal. However, many types of biodegradable or permanent scaffolds made of natural (collagen, hyaluronic acid, chitosan and chitin) or synthetic (polylactic acid, polyglycolic acid, tricalcium phosphate, hydroxyapatite) materials are available $(39,40)$. Recently, peptide hydrogel nanofibers and various fibrin gels have been investigated as potential scaffolds for dental pulp tissue engineering (41).

Collagen is the most widely studied natural scaffold. The most widely used synthetic scaffolds are polymers of lactide and glycolide. In regenerative endodontics, a tissue engineered pulp is not required to provide structural support to the tooth. So, engineered pulp tissue can be administered in a soft threedimensional scaffold matrix, such as polymer hydrogel (42), which can be injected at the site (injectable scaffold delivery). Hydrogels have similar physical properties as that of living tissue, which is due to their high water content, soft and rubbery consistency and low interfacial tension with water or biological fluids. Research is focusing on making hydrogels photo-polymerizable (43) or self-hardening e.g., silanized hydroxyl-propylmethyl cellulose,(44) so that they form rigid structures once they are implanted into the tissue sites. Another injectable scaffold studied is $\beta$-tricalcium phosphate (45). It is alginate in gel phase and forms beads in solid phase. Other materials that have been tried and tested as scaffold structures are fibronectin, MTA, fibrous titanium mesh, treated dentine, enamel matrix derivatives (Emdogain) and biodegradable porous calcium phosphate $(15,46)$.

The triad of DPSCs, collagen scaffold, and Dentin Matrix Protein (DMP)-1 were placed in simulated perforation sites in dentin slices. After 6 weeks of subcutaneous implantation on the dorsal surfaces of immunodeficient mice, organized matrix formation similar to that of pulpal tissue was seen which might lead to hard tissue formation. In the group using only collagen scaffold, degrading collagen was observed without the presence of any calcified tissues (47). Collagen gel solution was successfully used in a cell-homing approach to regeneration along with multiple combined growth factors such as beta-Fibroblast Growth Factor (bFGF), Vascular Endothelial Growth Factor (VEGF), or Platelet-Derived Growth Factor (PDGF) with a basal set of Nerve Growth Factor (NGF) and Bone Morphogenetic Protein-7 (BMP7) (48).

\subsection{Growth factors}

Growth factors are proteins that bind to receptors on the cell and act as signals to induce cellular proliferation and/or differentiation (49). Examples of key growth factors in pulp and dentin formation include bone morphogenetic protein (50), transforming growth factor-beta (51) and fibroblastic growth factor (52). Current REPs aim to utilize growth factors found in platelets (41) and dentin (53). Recent studies have shown that dentin contains a number of bioactive molecules that, when released, play an important role in regenerative procedures $(53,54)$.

Thus, the potential use of growth factors in dentistry is in conjunction with stem cells to provide replacement of diseased tooth pulp via tissue engineering. A possible future prospect could be the incorporation of these growth factors in restorative and endodontic materials to stimulate dentin-pulp complex regeneration (15). How to deliver the growth factors effectively is one of the main challenges we are facing now. Direct application of growth factors often results in only temporary release. The limited half-life and unstable release of growth factors are unfavorable for new tissue formation. For this, an alternative approach is to deliver a gene that encodes for growth instead of delivering growth factors itself called gene therapy.

Mouse dental papilla cells transfected with growth/differentiation factor 11 (Gdf11) were demonstrated to express dentin sialoprotein (Dsp) (55); Osteo-dentin formation during pulpal wound healing was observed in dog teeth in vivo after Gdf11 electroporation. The same group also used Gdf11 ultrasound-mediated gene delivery using microbubbles, demonstrating complete reparative dentin formation in animal model in vivo (56). The effectiveness of this kind of in vivo gene therapy highly depends on the vitality of the remaining dental pulp cells. Ex vivo gene therapy, involving the transfer of in vitro transfected cells back in vivo, may provide a better solution. The Nakashima group also proved that the transplanted Gdf11-electrotransfected pulp cell pellet stimulated reparative dentin formation (57). 


\section{Vascular endothelial growth factor (VEGF)}

The tissue engineering triad of scaffold, stem cells and morphogens might be essential for successful pulp regeneration. However, without proper angiogenesis/vasculogenesis to supply enough nutrients and oxygen to the transplanted or migrated stem cells into the root canal, pulp regeneration would not be successful. VEGF is an excellent regulator of angiogenesis and is known to increase vascular permeability.

VEGF is a potent endothelial cell mitogen and angiogenic factor that has been shown to play a central role in vascular responses that accompany a number of physiological and pathological processes (58). VEGF induces chemotaxis, proliferation and differentiation of human dental pulp cells $(59,60)$. In addition, VEGF is also involved in the proliferation of endothelial cells, enhances their survival in the toxic oxygen-deficient environment, and stimulates neovascularization in the area of injury (61). In an in vivo study using the immunodeficient mice model, tooth slices treated with 0 or $50 \mathrm{ng} / \mathrm{mL}$ rhVEGF165 for one hour, demonstrated increased pulp microvessel density, which is potentially beneficial for pulp regeneration (62).

Dentin contains many growth factors including VEGF and cytokines that are embedded in the matrix during dentinogenesis through their interactions with non-collagenous proteins and other extracellular matrix components (63). Among these growth factors, angiogenic growth factors (VEGF) released from the matrix as a result of matrix breakdown during tissue injury or during pulp regeneration procedures by EDTA, could make an important contribution to the overall reparative/regenerative response of the dentine-pulp complex (64).

\section{Revascularization (Harnessing The Natural Regenerative Potential Of Dental Pulp)}

Translation of dental tissue-engineering approaches to the clinic will make considerable contributions to these outcomes in the future, but exploiting the natural regenerative potential of dentin-pulp to enhance wound-healing responses offers solutions for maintaining pulp vitality now. During the period of 1993-2007, several key publications prompted a reemergence of a biological or regenerative approach for endodontic treatment. During this period, several case reports were published in which immature permanent teeth with pulp necrosis were disinfected, followed by creating bleeding into canal system by overinstrumenting the apical tissue and placing a coronal restoration. The resulting clinical outcome was a resolution of sinus tracts, pain, and swelling and a dramatic increase in radiographic root length and width, which often occurred $0.5-2$ years after treatment $(37,65-68)$. A retrospective analysis by Bose et al (69) on 48 regenerative cases reported a significant increase in radiographic root development for both root length and root width as compared with MTA apexification procedures. These findings were recently replicated in an independent patient population (70), which extended the original findings of Bose et al by demonstrating significantly greater tooth survival after regenerative treatment (100\%) compared with teeth treated with $\mathrm{Ca}(\mathrm{OH}) 2$ apexification $(77 \%)$. Although caution must be applied to these clinical findings because case reports may be biased for reporting positive outcomes, the preponderance of publications to date suggest that regenerative endodontic treatment of the immature permanent tooth can lead to healing of apical periodontitis, continued radiographic root development, and improved tooth survival.

\section{Consideration For Regenerative Procedures (71)}

4.1 Case selection:

- Tooth with necrotic pulp and an immature apex

- Pulp space not needed for post/core, final restoration

- Compliant patient

\subsection{Informed consent:}

- Two (or more) appointments

- Use of antimicrobial(s)

- Possible adverse effects: staining of crown/root, lack of response to treatment, pain/infection

- Alternatives: MTA apexification, no treatment, extraction (when deemed nonsalvageable)

- Permission to enter information into AAE database (optional)

\subsection{First appointment:}

- Local anesthesia, rubber dam isolation, access

- Copious, gentle irrigation with $20 \mathrm{~mL} \mathrm{NaOCl}$ using an irrigation system that minimizes the possibility of extrusion of irrigants into the periapical space (eg, needle with closed end and side vents, or EndoVac). To minimize potential precipitate in the canal, use sterile water or saline between $\mathrm{NaOCl}$; lower concentrations of $\mathrm{NaOCl}$ are advised, to minimize cytotoxicity to stem cells in the apical tissues.

- Dry canals 
- Place antibiotic paste or calcium hydroxide. If the triple antibiotic paste is used: (1) consider sealing pulp chamber with a dentin bonding agent to minimize risk of staining, and (2) mix 1:1:1

ciprofloxacin/metronidazole/minocycline (or, if esthetics are crucial, then consider a 1:1 mixture of ciprofloxacin/metronidazole).

- Deliver into canal system via lentulo spiral, MAP system, or Centrix syringe

- If triple antibiotic paste is used, ensure that it remains below the CEJ (to minimize crown staining)

- Seal with 3 to $4 \mathrm{~mm}$ of Cavit, followed by immediate restorative material, glass ionomer cement, or another temporary material

- Dismiss patient for 3 to 4 weeks

\subsection{Second appointment:}

- Assess response to initial treatment. If there are signs/symptoms of persistent infection, consider additional treatment time with antimicrobial, or alternative antimicrobial.

- Anesthesia with $3 \%$ mepivacaine without vasoconstrictor, rubber dam, isolation

- Copious, gentle irrigation with $20 \mathrm{~mL}$ of ethylenediamine tetraacetic acid, followed by normal saline, using a similar closed-end needle

- Dry with paper points

- Create bleeding into canal system by overinstrumenting (endo file, endo explorer)

- Stop bleeding $3 \mathrm{~mm}$ from CEJ

- Place CollaPlug/CollaCote at the orifice, if necessary

- Place 3 to $4 \mathrm{~mm}$ of white MTA and reinforced glass ionomer and place permanent restoration

\subsection{Follow-up:}

Clinical and radiographic examination:

- No pain or soft tissue swelling (often observed between first and second appointments)

- Resolution of apical radiolucency (often observed 6-12 months after treatment)

- Increased width of root walls (this is generally observed before apparent increase in root length and often occurs 12-24 months after treatment)

- Increased root length (71).

\section{What Tissue Is In The Canal?}

Previous reports have shown the re-establishment of pulp-like tissue in canals that were previously void of pulp tissue (72) or had necrotic tissue present (73). However, histology after REPs in dogs shows that the radiographic changes in the root may be from the deposition of cementum-like and bone-like tissues (74), suggesting ingrowth of periodontal ligament tissue versus pulp tissue. Furthermore, Wang et al (75) reported histologic evidence from dogs suggesting that increased root length and thickness were from apposition of cementum-like tissue. The likelihood of achieving regeneration of pulp tissue versus other tissues may be estimated based on a study by Ritter et al (76) in which approximately 30\% of replanted dog teeth had pulp tissue reentering the canal space. A recent review by Andreasen and Bakland (77) based on an analysis of more than 1200 traumatized teeth and 370 autotransplanted premolars provides additional information regarding possible outcomes. They described 4 types of healing outcomes:

1. Revascularization of the pulp with accelerated dentin formation leading to pulp canal obliteration

2. Ingrowth of cementum and periodontal ligament (PDL)

3. Ingrowth of cementum, PDL, and bone

4. Ingrowth of bone and bone marrow

Recent histologic evidence from 2 cases reports suggests that regenerated pulp tissue may be in the canal space after REPs(78,79). However the study conducted by Martin et al $(80)$ where histological analysis of teeth has been possible after treatment by a simple revascularisation procedure or by application of plateletrich plasma, deposition of a mineralised layer on the radicular walls was observed, which appeared to be of periodontal rather than pulpal origin. This suggests that the new tissue was not of dentinogenic origin and emphasises the limitations of radiography for characterising new mineralised tissue formation in endodontics. Nevertheless, effective apical closure is a key goal of apexification techniques (81) and whether this is achieved with a dentinogenic or a periodontal structure might be of lesser

\section{Conclusion}

The aspect of dentine-pulp tissue engineering is of great interest with a large number of studies performed over the past several years. However, the science is still not able to allow clinical procedures to be performed routinely in humans. There are no clinical studies that can be routinely performed in an effort that 
will lead to dentine-pulp repair and regeneration (82). The hope of the research to date rests on the ability that the use of naturally occurring cells at the site of injury may lessen side-effect risks. Pulp revascularization procedures have shown promising results clinically. Although the new approach to treatment can at times be challenging and the outcome of revascularization procedures still remains somewhat unpredictable, they represent an improvement over older treatment protocols that have left the roots short and the walls of the root canal thin and prone to fracture. They also leave the door open to other methods of treatment besides extraction, when they fail to achieve the desire result.

It is important, however, to return to the objectives when trying to assess treatment success. If the objective is to induce healing of the periapical tissues, stimulate bone regeneration, and render the patient free from any signs or symptoms, then current regenerative treatments can be regarded a clinical success (although perhaps a biological failure). Filling the root canal space with a vital biological tissue has the significant advantage of providing an immuno-competent root canal filling with defensive capabilities for any future bacterial exposure like normal pulp tissue. Nevertheless, reports of some of the experimental studies involving recruitment of specific stem/progenitor cell populations and exploit endogenous signalling molecules sequestered in dentine to regenerate dentine-pulp tissue with physiological characteristics suggest that true pulpdentine regeneration may be a clinical reality in future

\section{References}

[1]. Langer R, Vacanti JP. Tissue engineering. Science 1993;260:920-6.

[2]. MacArthur BD, Oreffo ROC. Bridging the gap. Nature 2005;433:19.

[3]. Glendor U, Andreasen JO. Classification, epidemiology and etiology. In: Andreasen JO, Andreasen FM, Andersson L, eds. Traumatic injuries to the teeth 4th ed. (Oxford: Blackwell Munksgaard; 2007) 217-54.

[4]. Hargreaves KM, Diogenes A, Teixeira FB. Treatment options: biological basis of regenerative endodontic procedures. J Endod. 2013 Mar;39:S30-43.

[5]. Neha K1, Kansal R, Garg P, Joshi R, Garg D, Grover HS. Management of immature teeth by dentin-pulp regeneration: a recent approach. Med Oral Patol Oral Cir Bucal. 2011 Nov 1;16(7):e997-1004.

[6]. Ostby BN. The role of the blood clot in endodontic therapy. An experimental histologic study. Acta Odontol Scand. 1961;19:32453.

[7]. Rule DC, Winter GB. Root growth and apical repair subsequent to pulpal necrosis in children. Br Dent J. 1966;120:586-90.

[8]. Nygaard-Ostby B, Hjortdal O. Tissue formation in the root canal following pulp removal. Scand J Dent Res. 1971;79:333-49.

[9]. Glossary of Endodontic Terms, 8th edition [Internet]. Chicago: American Association of Endodontists, 2012. Available from: http://www.nxtbook.com/nxtbooks/aae/ endodonticglossary/index.php.

[10]. Lysagth MJ, Reyes J. The growth of tissue engineering. Tissue Eng 2001;7:485-93.

[11]. Nakashima M, Reddi AH. The application of bone morphogenetic proteins to dental tissue engineering. Nat Biotechnol 2003;21:1025-32.

[12]. Rao MS. Stem sense: a proposal for the classification of stem cells. Stem Cells Dev 2004; 13: 452-5.

[13]. Fortier LA. Stem cells: classifications, controversies, and clinical applications. Vet Surg 2005; 34: 415-23.

[14]. Gardner RL. Stem cells: potency, plasticity and public perception. J Anat 2002; 200: 277-82.

[15]. Malhotra N, Mala K. Regenerative endodontics as a tissue engineering approach: past, current and future. Aust Endod J. 2012 Dec;38(3):137-48.

[16]. Gimble J, Guilak F. Adipose-derived adult stem cells: isolation, characterization, and differentiation potential. Cytotherapy 2003;5:362-369.

[17]. Casagrande L, Mattuella LG, de Araujo FB, Eduardo J. Stem cells in dental practice: perspectives in conservative pulp therapies. J Clin Pediatr Dent 2006;31:25-27.

[18]. Trubiani O, D’Arcangelo C, Di Iorio D, Di Nardo Di Maio F, Caputi S. Dental pulp stem cells bioadhesivity: evaluation on mineraltrioxide- aggregate. Int J Immunopathol Pharmacol 2007;20:81-86.

[19]. Gronthos S, Mankani M, Brahim J, Robey PG, Shi S. Postnatal human dental pulp stem cells (DPSCs) in vitro and in vivo. Proc Natl Acad Sci USA 2000;97:13625-13630.

[20]. Miura M, Gronthos S, Zhao M, Lu B, Fisher LW, Robey PG, Shi S. SHED: stem cells from human exfoliated deciduous teeth. Proc Natl Acad Sci USA 2003; 100: 5807-5812.

[21]. Sonoyama W, Liu Y, Fang D, Yamaza T, Seo BM, Zhang C, Liu H, Gronthos S, Wang CY, Shi S, Wang S. Mesenchymal stem cell-mediated functional tooth regeneration in swine. PLoS One 2006; 1: e79.

[22]. Sonoyama W, Liu Y, Yamaza T, Tuan RS, Wang S, Shi S, Huang GT. Characterization of the apical papilla and its residing stem cells from human immature permanent teeth: a pilot study. J Endod 2008;34:166-171.

[23]. Seo BM, Miura M, Gronthos S, Bartold PM, Batouli S, Brahim J, Young M, Robey PG, Wang CY, Shi S. Investigation of multipotent postnatal stem cells from human periodontal ligament. Lancet 2004;364:149-155.

[24]. Sedgley CM, Botero TM. Dental stem cells and their sources. Dent Clin North Am. 2012 Jul;56(3):549-61

[25]. Chopra H, Hans MK, Shetty S. Stem cells-the hidden treasure: A strategic review. Dental Research Journal.2013 Jul;10(4):421-427

[26]. El-Backly RM, Massoud AG, El-Badry AM, Sherif RA, Marei MK. Regeneration of dentine/pulp-like tissue using a dental pulp stem cell/ poly(lactic-co-glycolic) acid scaffold construct in New Zealand white rabbits. Aust Endod J 2008;34:52-67.

[27]. Nakamura S, Yamada Y, Katagiri W, Sugito T, Ito K, Ueda M. Stem cell proliferation pathways comparison between human exfoliated deciduous teeth and dental pulp stem cells by gene expression profile from promising dental pulp. J Endod 2009;35:1536-42.

[28]. Govindasamy V, Abdullah AN, Ronald VS, Musa S, Ab Aziz ZA, Zain RB, et al. Inherent differential propensity of dental pulp stem cells derived from human deciduous and permanent teeth. J Endod 2010;36:1504-15.

[29]. Yang ZH, Zhang XJ, Dang NN, Ma ZF, Xu L, Wu JJ, et al. Apical tooth germ cell-conditioned medium enhances the differentiation of periodontal ligament stem cells into cementum/periodontal ligament-like tissues. J Periodontal Res 2009;44:199-210.

[30]. Nakashima M, Iohara K. Regeneration of dental pulp by stem cells. Adv Dent Res. 2011;23(3):313-9.

[31]. Nosrat A, Ryul Kim J, Verma P, S Chand P. Tissue Engineering Considerations in Dental Pulp Regeneration.. Iran Endod J. 2014 Winter; 9(1): 30-39 
[32]. Alongi DJ, Yamaza T, Song Y, Fouad AF, Romberg EE, Shi S, Tuan RS, Huang GT. Stem/progenitor cells from inflamed human dental pulp retain tissue regeneration potential. Regen Med. 2010;5(4):617-31.

[33]. Bohl KS, Shon J, Rutherford B, et al. Role of synthetic extracellular matrix in development of engineered dental pulp. J Biomater Sci Polym Ed 1998:9:749-64.

[34]. Young CS, Abukawa H, Asrican R, Ravens M, Troulis MJ, Kaban LB, et al. Tissue-engineered hybrid tooth and bone. Tissue Eng 2005;11: 1599-610.

[35]. Taylor MS, Daniels AU, Andriano KP, Heller J. Six bioabsorbable polymers: in vitro acute toxicity of accumulated degradation products. J Appl Biomater 1994;5:151-7.

[36]. Karande TS, Ong JL, Agarwal CM. Diffusion in musculoskeletal tissue engineering scaffolds: design issues related to porosity, permeability, architecture, and nutrient mixing. Ann Biomed Engl 2004;32:1728-43.

[37]. Banchs F, Trope M. Revascularization of immature permanent teeth with apical periodontitis: new treatment protocol? J Endod 2004:30:196-200.

[38]. Torabinejad M, Turman M. Revitalization of tooth with necrotic pulp and open apex by using platelet-rich plasma: a case report. J Endod 2011;37:265-8.

[39]. Gotlieb EL, Murray PE, Namerow KN, et al. An ultrastructural investigation of tissue-engineered pulp constructs implanted within endodontically treated teeth. J Am Dent Assoc 2008;139:457-65.

[40]. Chandrahasa S, Murray PE, Namerow KN. Proliferation of mature ex vivo human dental pulp using tissue engineering scaffolds. J Endod 2011;37:1236-9.

[41]. Galler KM, Hartgerink JD, Cavender AC, et al. A customized self-assembling peptide hydrogel for dental pulp tissue engineering. Tissue Eng Part A 2012;18:176-84.

[42]. Trojani C, Weiss P, Michiels JF, Vinatier C, Guicheux J, Daculsi G, et al.Three-dimensional culture and differentiation of human osteogenic cells in an injectable hydroxypropylmethylcellulose hydrogel. Biomater 2005;26:5509-17.

[43]. Luo Y, Shoichet MS. A photolabile hydrogel for guided threedimensional cell growth and migration. Nat Mater 2004;3:249-53.

[44]. Weiss P, Vinatier C, Sohier J, Fatimi A, Layrolle P, Demais V, et al. Selfhardening hydrogel for bone tissue engineering. Macromolecular Symposia 2008;266:30-5.

[45]. Matsuno T, Hashimoto Y, Adachi S, Omata K, Yoshitaka Y, Ozeki Y, et al. Preparation of injectable 3D-formed beta-tricalcium phosphate bead/alginate composite for bone tissue engineering. Dent Mater J 2008;27:827-34.

[46]. Bansal R, Bansal R. Regenerative endodontics: a state of the art. Indian J Dent Res. 2011 Jan-Feb;22(1):122-31.

[47]. Prescott RS, Alsanea R, Fayad MI, Johnson BR, Wenckus CS, Hao J, John AS, George A. In vivo generation of dental pulp-like tissue by using dental pulp stem cells, a collagen scaffold, and dentin matrix protein 1 after subcutaneous transplantation in mice. J Endod. 2008;34(4):421-6.

[48]. Kim JY, Xin X, Moioli EK, Chung J, Lee CH, Chen M, Fu SY, Koch PD, Mao JJ. Regeneration of dental-pulp-like tissue by chemotaxis-induced cell homing. Tissue Eng Part A. 2010;16(10):3023-31.

[49]. Murray PE, Garcia-Godoy F, Hargreaves KM. Regenerative endodontics: a review of current status and a call for action. J Endod 2007;33:377-90

[50]. Nakashima M. Bone morphogenetic proteins in dentin regeneration for potential use in endodontic therapy. Cytokine Growth Factor Rev 2005;16:369-76.

[51]. Chan CP, Lan WH, Chang MC, et al. Effects of TGF-betas on the growth, collagen synthesis and collagen lattice contraction of human dental pulp fibroblasts in vitro. Arch Oral Biol 2005;50:469-79.

[52]. Ishimatsu H, Kitamura C, Morotomi T, et al. Formation of dentinal bridge on surface of regenerated dental pulp in dentin defects by controlled release of fibroblast growth factor-2 from gelatin hydrogels. J Endod 2009;35:858-65.

[53]. Smith AJ, Scheven BA, Takahashi Y, et al. Dentine as a bioactive extracellular matrix. Arch Oral Biol 2012;57:109-21.

[54]. Sun HH, Jin T, Yu Q, et al. Biological approaches toward dental pulp regeneration by tissue engineering. J Tissue Eng Regen Med 2011;5:e1-16.

[55]. M. Nakashima, K.Mizunuma, T.Murakami, and A. Akamine, "Induction of dental pulp stem cell differentiation into odontoblasts by electroporation-mediated gene delivery of growth/differentiation factor 11 (Gdf11)," Gene Therapy, vol. 9, no. 12, pp. 814-818, 2002.

[56]. M. Nakashima, K. Tachibana, K. Iohara, M. Ito, M. Ishikawa, and A. Akamine, "Induction of reparative dentin formation by ultrasound-mediated gene delivery of Growth/differentiation factor 11," Human Gene Therapy, vol. 14, no. 6, pp. 591-597, 2003.

[57]. M. Nakashima, K. Iohara, M. Ishikawa, et al., "Stimulation of reparative dentin formation by ex vivo gene therapy using dental pulp stem cells electrotransfected with growth/differentiation factor 11 (Gdf11)," Human Gene Therapy, vol. 15, no. 11, pp. 1045-1053, 2004.

[58]. Ferrara N, Bunting S. Vascular endothelial growth factor, a specific regulator of angiogenesis. Curr Opin Nephrol Hypertens. 1996;5(1):35-44.

[59]. Artese L, Rubini C, Ferrero G, Fioroni M, Santinelli A, Piattelli A. Vascular endothelial growth factor (VEGF) expression in healthy and inflamed human dental pulps. J Endod. 2002;28(1):20-3.

[60]. Matsushita K, Motani R, Sakuta T, Yamaguchi N, Koga T, Matsuo K, Nagaoka S, Abeyama K, Maruyama I, Torii M. The role of vascular endothelial growth factor in human dental pulp cells: induction of chemotaxis, proliferation, and differentiation and activation of the AP-1-dependent signaling pathway. J Dent Res. 2000;79(8):1596-603.

[61]. Nor JE, Christensen J, Mooney DJ, Polverini PJ. Vascular endothelial growth factor (VEGF)-mediated angiogenesis is associated with enhanced endothelial cell survival and induction of Bcl-2 expression. Am J Pathol. 1999;154(2):375-84.

[62]. Mullane EM, Dong Z, Sedgley CM, Hu JC, Botero TM, Holland GR, Nor JE. Effects of VEGF and FGF2 on the revascularization of severed human dental pulps. J Dent Res. 2008;87(12):1144-8.

[63]. Smith AJ. Vitality of the dentin-pulp complex in health and disease: growth factors as key mediators. J Dent Educ. 2003;67(6):67889.

[64]. Roberts-Clark DJ, Smith AJ. Angiogenic growth factors in human dentine matrix. Arch Oral Biol. 2000;45(11):1013-6.

[65]. Iwaya SI, Ikawa M, Kubota M. Revascularization of an immature permanent tooth with apical periodontitis and sinus tract. Dent Traumatol 2001;17:185-7.

[66]. Chueh LH, Huang GT. Immature teeth with periradicular periodontitis or abscess undergoing apexogenesis: a paradigm shift. J Endod 2006;32:1205-13.

[67]. Petrino JA. Revascularization of necrotic pulp of immature teeth with apical periodontitis. Northwest Dentistry 2007;86:33-5.

[68]. Thibodeau B, Trope M. Pulp revascularization of a necrotic infected immature permanent tooth: case report and review of the literature. Pediatr Dent 2007; 29:47-50. 
[69]. Bose R, Nummikoski P, Hargreaves K. A retrospective evaluation of radiographic outcomes in immature teeth with necrotic root canal systems treated with regenerative endodontic procedures. J Endod 2009;35:1343-9.

[70]. Jeeruphan T, Jantarat J, Yanpiset K, et al. Mahidol study 1: comparison of radiographic and survival outcomes of immature teeth treated with either regenerative endodontic or apexification methods - a retrospective study. J Endod 2012;38: 1330-6.

[71]. Geisler TM. Clinical Considerations forRegenerative EndodonticProcedures. Dent Clin North Am. 2012 Jul;56(3):603-26.

[72]. Heithersay GS. Stimulation of root formation in incompletely developed pulpless teeth. Oral Surg Oral Med Oral Pathol 1970;29:620-30.

[73]. Lin L, Shovlin F, Skribner J, et al. Pulp biopsies from the teeth associated with periapical radiolucency. J Endod 1984;10:436-48.

[74]. Thibodeau B, Teixeira F, Yamauchi M, et al. Pulp revascularization of immature dog teeth with apical periodontitis. J Endod 2007;33:680-9.

[75]. Wang $\mathrm{X}$, Thibodeau $\mathrm{B}$, Trope $\mathrm{M}$, et al. Histologic characterization of regenerated tissues in canal space after the revitalization/revascularization procedure of immature dog teeth with apical periodontitis. J Endod 2010;36:56-63.

[76]. Ritter AL, Ritter AV, Murrah V, et al. Pulp revascularization in replanted immature dog teeth after treatment with minocycline and doxycycline assessed by laser Doppler flowmetry, radiography, and histology. Dent Traumatol 2004;20:75-84.

[77]. Andreasen JO, Bakland LK. Pulp regeneration after non-infected and infectednecrosis, what type of tissue do we want? A review. Dent Traumatol 2011;28:13-8.

[78]. Torabinejad M, Faras H. A clinical and histological report of a tooth with an open apex treated with regenerative endodontics using platelet-rich plasma. J Endod 2012;38:864-8.

[79]. Shimizu E, Jong G, Partridge N, et al. Histologic observation of a human immature permanent tooth with irreversible pulpitis after revascularization/regeneration procedure. J Endod 2012;38:1293-7.

[80]. Martin G, Ricucci D, Gibbs J L, Lin L M. Histological findings of revascularized/revitalized immature permanent molar with apical periodontitis using platelet-rich plasma. J Endod 2013; 39: 138-144.

[81]. Simon S, Rilliard F, Berdal A, Machtou P. The use of mineral trioxide aggregate in one-visit apexification treatment: a prospective study. Int Endod J 2007; 40: 186-197

[82]. Mitisiadis TA, Feki A, Papaccio G, et al. Dental pulp stem cells, niches, and NOTCH signaling in tooth injury. Adv Dent Res 2011;23(3):275-9 